\title{
Dispersal pattern of the sand fly Lutzomyia neivai (Diptera: Psychodidae) in a cutaneous leishmaniasis endemic rural area in Southeastern Brazil Cláudio Casanova/ ${ }^{+}$, Antonio IP Costa, Delsio Natal*
}

Superintendência de Controle de Endemias, Rua Afonso Pessini 86, 13845-206 Mogi Guaçu, SP, Brasil *Faculdade de Saúde Pública, USP, São Paulo, SP, Brasil

The dispersal pattern of the sand fly Lutzomyia neivai was studied through mark-release-recapture experiments in an American cutaneous leishmaniasis endemic rural area in Southeastern Brazil. Over 6500 specimens were marked with fluorescent powder and released in forest edge and peridomicile habitats from August to November 1999, February and April 2000. Recapture attempts were made using Shannon and CDC traps up to eight successive nights after releases. A total of 493 (7.58\%) specimens were recaptured. The number of recaptured males and females of L. neivai in CDC traps was not affected by the distance between the trap and the release points. Approximately $90 \%$ of males and females recaptured in CDC traps were caught up to $70 \mathrm{~m}$ from the release points. The maximum female flight range recorded was $128 \mathrm{~m}$. The average flight range per day was less than $60 \mathrm{~m}$ for males and females. Of the flies released in forest edge, approximately $16 \%$ of the recaptured females were caught in Shannon traps in the peridomicile habitat. The results indicate that the movements of $\mathrm{L}$. neivai are spatially focal and the possibility of dispersion from forest to peridomicile habitat may be an important way of contracting leishmaniasis in dwellings.

Key words: mark-release-recapture - dispersal - sand fly - Lutzomyia neivai - Brazil

Information on the dispersion pattern of sand flies vectors in nature can be used to evaluate the potential rate of Leishmania dissemination and to implement surveillance and control strategies against these vectors.

Previous dispersal studies have shown that species from Old World arid and semi-arid regions may fly more than 1500 m (Killick-Kendrick et al. 1984, Doha et al. 1991), while sand flies from Neotropical forests seldom travel no more than $200 \mathrm{~m}$ from their release point (Chaniotis et al. 1974, Alexander 1987, Alexander \& Young 1992, Morrison et al. 1993).

In Brazil, the Lutzomyia longipalpis (Lutz \& Neiva) dispersal patterns have been studied (Dye et al. 1991, Kelly \& Dye 1997), but there is no study of the dispersal pattern of the vectors of American cutaneous leishmaniasis (ACL). In the Southeastern region of Brazil, the forest seems to be the environment of the enzootic cycle of Leishmania (Viannia) braziliensis (Gomes et al. 1989, Gomes 1994, Lainson et al. 1994), and it is mostly in the domiciliary habitat that man becomes infected (Rangel et al. 1990, Gomes 1994, Tolezano 1994, Gontijo et al. 2002). Thus the flight range and the dispersion of sand flies between these habitats are important factors in ACL transmission.

The present study was carried out to describe the dispersal pattern of Lutzomyia neivai (Pinto, 1926), recently resurrected as species of the complex Lutzomyia in-

$\overline{\text { Financial support: Sucen, } \mathrm{CNP}} \mathrm{q}$

${ }^{+}$Corresponding author. E-mail: casanova@ directnet.com.br Received 12 August 2005

Accepted 25 October 2005 termedia (Lutz \& Neiva, 1912) by Marcondes (1996), in an ACL endemic rural area in Southeastern of Brazil, by the mark-release-recapture technique. The anthropophilic behavior of the species, its predominance in modified environments and its presence in houses were people have become infected indicates L. neivai as the suspected vector in a large area (Gomes 1994, Tolezano 1994, Casanova et al. 1995, Marcondes et al. 1998, Teodoro et al. 2001, Salomon et al. 2003, 2004, Andrade Filho et al. 2003).

\section{MATERIALS AND METHODS}

Study area - The study was carried out in an ACL endemic rural area in municipality of Conchal $\left(22^{\circ} 18^{\prime} \mathrm{S}\right.$ and 4713'W), Mogi Guaçu River Valley, São Paulo (Fig. 1). This locality has a secondary remnant gallery forest, which covers the left margin of Mogi Guaçu river (Fig. 1), small farms with fruit-trees, vegetables, and domestics animals such as chickens and pigs. According to the Köeppen classification, the climate is subtropical warm with dry winter (Cwa). The average annual rainfall is $1381 \mathrm{~mm}$ and the average annual temperature is $21.6^{\circ} \mathrm{C}$. Previous studies demonstrated that L. neivai is the predominant species in this area (Casanova et al. 1995, Casanova 2000).

Mark-release-recapture experiments - Mark-releaserecapture experiments were performed with wild-caught sand flies from August 1999 to April 2000.

The sand flies were caught using the Castro aspirator (Alexander 2000) in modified Shannon traps (Vexenat et al. 1986) from $18 \mathrm{~h}$ to $21 \mathrm{~h}$. The sand flies were counted and transferred to a Styrofoam cage $(20 \times 13 \times 18 \mathrm{~cm})$ with a thin layer plaster of Paris (Fig. 2) and then marked with fluorescent powder (red, white, yellow, and blue - Bioquip Inc.) according to the date and site. The powder was dispersed into the cage by puffing air in a separate powder 
compartment ( $5 \mathrm{~cm}$ diameter), similar to the one used by Pardo et al. (1996), which was connected by a hole $(5 \mathrm{~cm}$ diameter) covered with a metal screen $\left(0.40 \mathrm{~mm}^{2}\right)$ to the cage. Another opening ( $2.5 \mathrm{~cm}$ diameter) covered with the same metal screen was made in the side of the cage to increase the air circulation during dusting (Fig. 2).
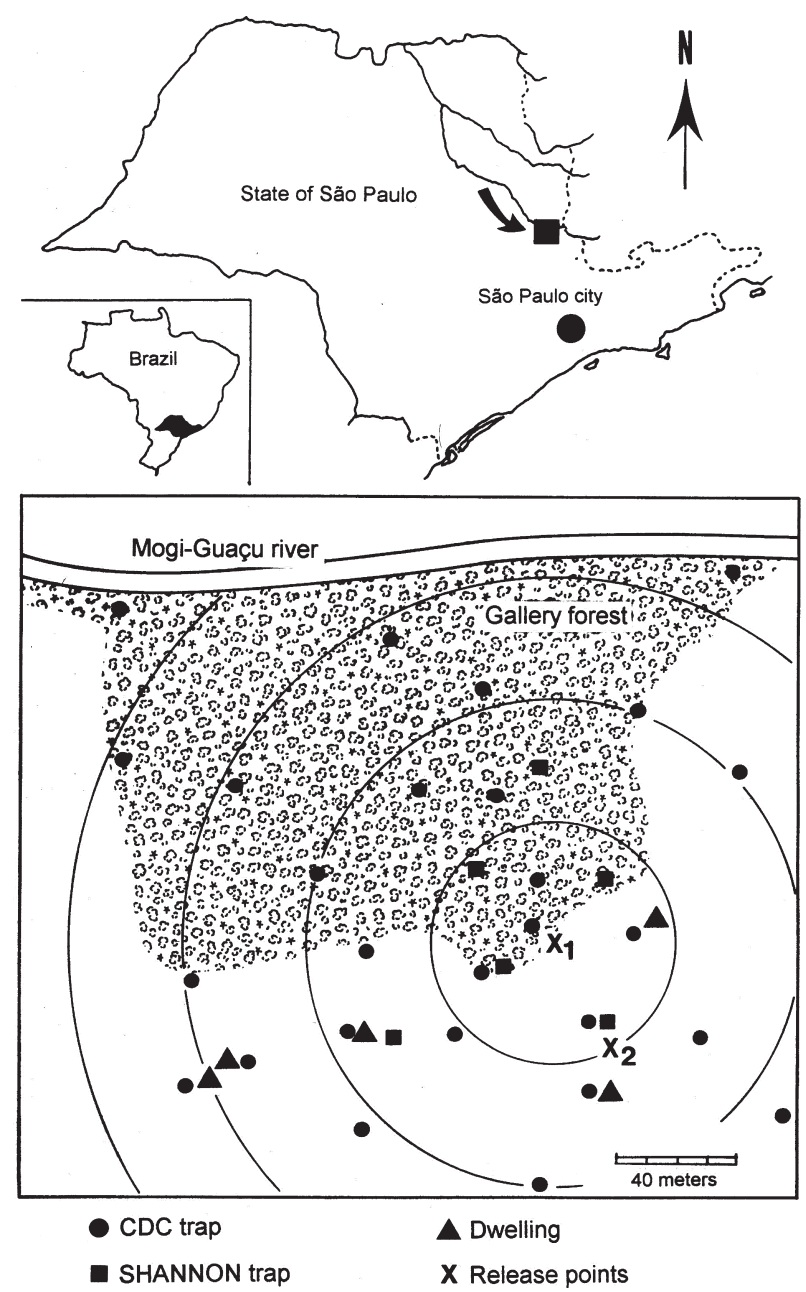

Fig. 1: study area.
The sand flies were released immediately after dusting from their capture sites on the edge of the forest. In two experiments, the flies were also released from a peridomicile site. Recapture attempts were performed for 5-8 successive nights after the release night using six Shannon traps and for 3-4 nights using 16-20 CDC traps. Two Shannon traps were set, from $18 \mathrm{~h}$ to $21 \mathrm{~h}$, in forest, forest edge, and peridomicile habitats, between $25 \mathrm{~m}$ and $90 \mathrm{~m}$ from the release points (Fig. 1). The CDC traps were operated from $18 \mathrm{~h}$ to $7 \mathrm{~h}$ at $5 \mathrm{~m}$ to $200 \mathrm{~m}$ from the release points in the three habitats (Fig. 1). The material collected was taken to the laboratory and marked and unmarked sand flies were separated under a stereomicroscope and black-light-blue for fluorescence. All sand flies were prepared (phenol potassium hidroxid - acetic acid - acid fucsin - etilic alcohol - and vegetal creosote) according to Forattini (1973) and identified according to Young and Duncan (1994).

The number of marked individuals recaptured in each CDC traps was transformed to $1 \mathrm{n}(\mathrm{y}+1)$ and regressed as a function of traps distance from the release points. The mean distance dispersed per day was estimated only for the November experiment, when the number of recaptured individuals in CDC traps was large enough. CDC trap collections were grouped into $40 \mathrm{~m}$ annuli from the point of release situated at the forest edge and adjusted by a correction factor, to accommodate unequal trap density, by the method of Brenner et al. (1984). The chi-square test was used to establish statistical differences in the proportions of males and females recaptured in Shannon traps between pairs in the forest, the forest edge, and the peridomicile habitats.

Two laboratory experiments were carried out to determine the effect of the fluorescent powders on the sand flies' longevity. For each experiment, two lots of 30 males and 40 females of wild-caught $L$. neivai were transferred to two Styrofoam cages $(20 \times 12 \times 15 \mathrm{~cm})$ and one sample was dusted, as described above. Each sample was released in holding cages $(20 \times 20 \mathrm{~cm})$ with $10 \%$ sucrose solution available and was maintained under laboratory conditions $\left(26^{\circ} \mathrm{C}\right.$ and $\left.82 \% \mathrm{RH}\right)$. The number of dead males and females was recorded daily for 10 days. All sand flies were processed and identified. For statistical analysis, the untransformed number of males and females marked and

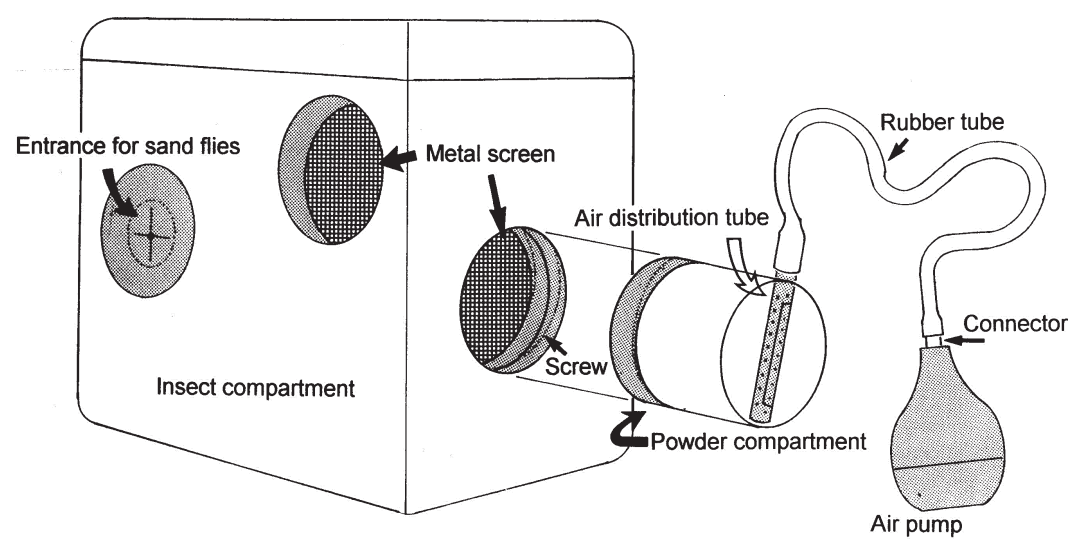

Fig. 2: the marking device. 
unmarked of $L$. neivai was regressed as a function on time in days. Each regression coefficient was tested for significant departure from zero by ANOVA and comparison among regression coefficient were made by ANCOVA (Sokal \& Rohlf 1995).

\section{RESULTS}

Laboratory experiments - In the control experiments (Fig. 3) the untransformed data provided a significant linear fit $(\mathrm{p}<0.05)$ and the regression coefficient and adjusted mean did not differ significantly $(p>0.05)$ in the covariance analysis. In the second experiment, marked females lived longer than the control (ANCOVA $<\mathrm{F}_{1 ; 18}=$ $6.243 ; \mathrm{p}=0.021$ ). Median life expectancies for marked and control were, respectively, 9 and 8 days for males and 8 and 9 for females in the first experiment and 7 and 6 days for males and 9 and 8 days for females in second experiment. The fluorescent powder was detected easily on individuals that died during the experimental period.

Field experiments - A total of 6502 specimens were marked. The device used allowed the simultaneous marking of 1485 individuals. All the sand flies, 2014 males and 4488 females, marked and released were presumed to be $L$. neivai, since more than $99 \%$ of the sand flies collected in the attempted recaptures, and all the recaptured individuals belonged to this species. A total of $188(9.3 \%)$ males and 305 (6.8\%) females of L. neivai were recaptured (Table I). Approximately $85 \%$ of males and $81 \%$ of females were recaptured in Shannon traps. In these traps, the male recapture rate $(7.9 \%)$ was significantly higher $\left(\chi^{2}=11.9\right.$, df $=1 ; \mathrm{p}<0.005)$ than the female rate $(5.5 \%)$ and in CDC traps these rates were similar (Table I).

The number of recaptured individuals in CDC traps transformed in $1 \mathrm{n}(\mathrm{y}+1)$ did not decrease significantly (for males: $\ln (y+1)=-0.001 x+1.122 ; p>0.75$, and for females: $\ln (y+1)=-0.003 x+1.414 ; p>0.55)$ as a curvilinear function of trap distance from the release points

\section{TABLE I}

Recapture rates of Lutzomyia neivai in CDC and Shannon traps in rural area of Conchal municipality, state of São Paulo, during August 1999 to April 2000

\begin{tabular}{llccc}
\hline & & \multicolumn{2}{c}{ Number (rate) recaptured } & \\
\cline { 3 - 4 } Sex & & Shannon & CDC & \\
\hline Male & 2014 & $159(7.9)$ & $29(1.4)$ & 9.3 \\
Female & 4488 & $248(5.5)$ & $57(1.3)$ & 6.8 \\
\hline
\end{tabular}

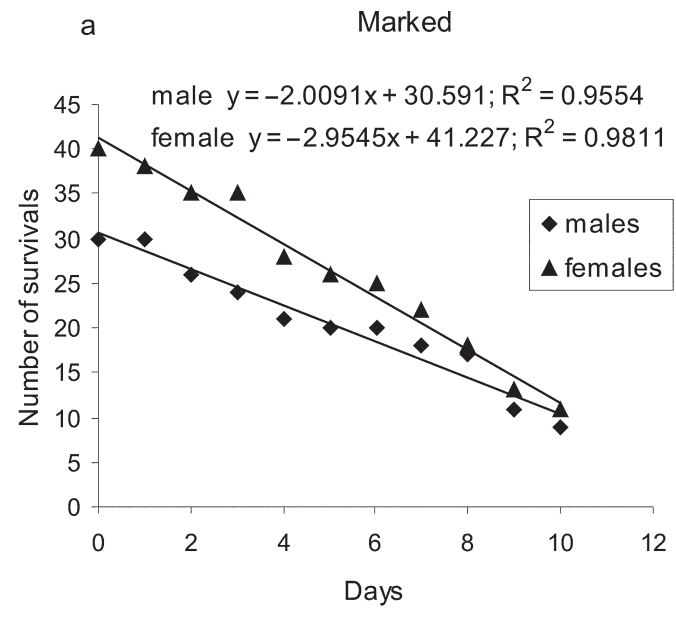

b

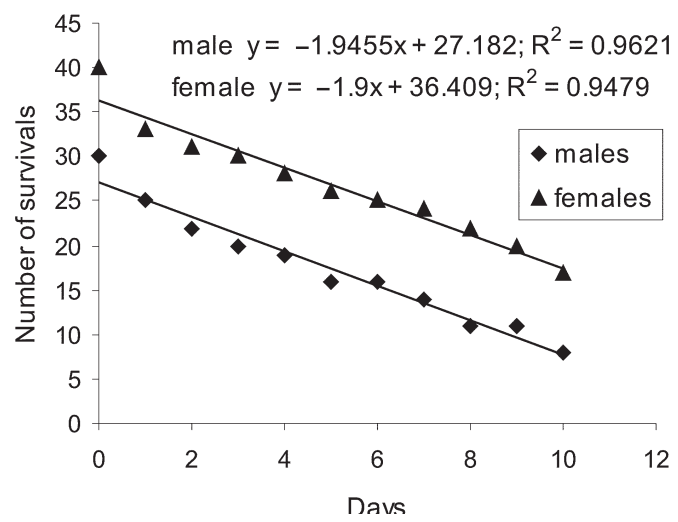

Unmarked

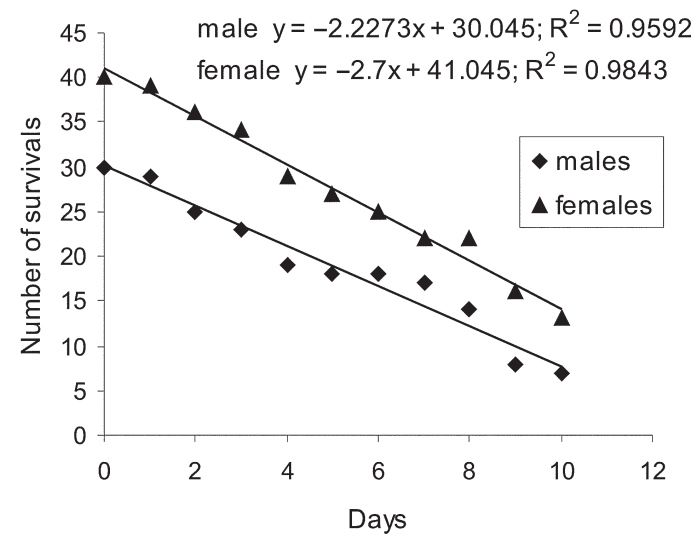

Unmarked

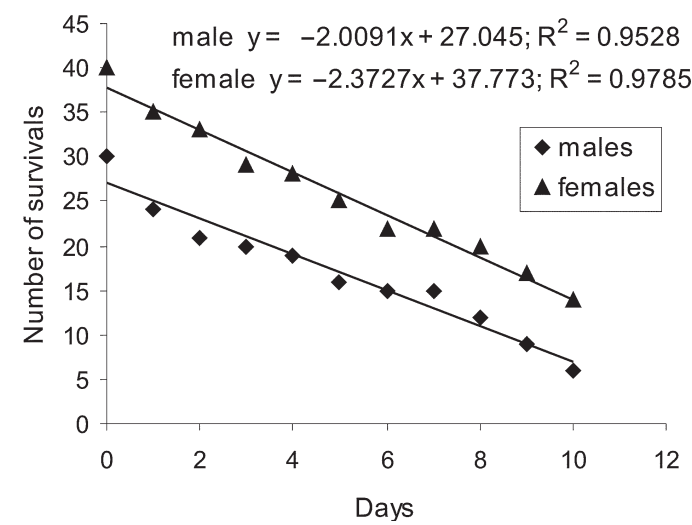

Fig. 3: survival curves for males and females of Lutzomyia neivai marked and control, in laboratory conditions. a: first experiment; b: second experiment. 
(Fig. 4). The arithmetic mean distance dispersed by the males was $53 \mathrm{~m}$ and by the females $55 \mathrm{~m}$ and $86 \%$ of the males and $89 \%$ of the females were recaptured up to $70 \mathrm{~m}$ of their release points. The maximum dispersion distance was $99 \mathrm{~m}$ for males and $128 \mathrm{~m}$ for females that were recaptured 7 and 8 days after their release. The longest period between release and recapture was 11 days for females and 14 days for males released.

The mean distance dispersed per day was calculated for 14 males and 45 females of L. neivai recaptured in the $16 \mathrm{CDC}$ traps during the November experiments and was adjusted for the area sampled. Mean dispersal distances were practically stable between 40 and $60 \mathrm{~m}$ for males and females released at the forest edge (Fig. 5).

Since the collection effort per habitat with Shannon traps was the same, it was possible to estimate the predominant direction of dispersion from the release point situated in forest edge based on the number of recaptured L. neivai. On three occasions for females (September, October, November) and two (October and November) for males there was a significant difference of dispersion in the Shannon traps situated in forest habitat, and on only one occasion for females (April) in the Shannon traps situated in peridomicile habitat (Table II). Pooling all the Shannon trap recaptures of females we found that $56.9 \%$ were from the forest, $27.4 \%$ were from the forest
TABLE II

Number of Lutzomyia neivai recaptured in Shannon traps in forest, forest edge, and peridomicile habitats in rural area of Conchal municipality, state of São Paulo, during August 1999 to April 2000

\begin{tabular}{|c|c|c|c|c|c|c|}
\hline \multirow[b]{3}{*}{ Month } & \multicolumn{6}{|c|}{ Habitat } \\
\hline & \multicolumn{2}{|c|}{ Forest } & \multicolumn{2}{|c|}{ Forest edge } & \multicolumn{2}{|c|}{ Peridomicile } \\
\hline & Male & Female & Male & Female & Male & Female \\
\hline Aug/99 & $28^{a}$ & $34^{b}$ & $35^{\mathrm{a}}$ & $55^{\mathrm{a}}$ & $13^{b}$ & $19^{\mathrm{c}}$ \\
\hline Sep/99 & $7^{a}$ & $18^{\mathrm{a}}$ & $3^{\mathrm{a}}$ & $2^{b}$ & $0^{b}$ & $6^{b}$ \\
\hline Oct/99 & $11^{\mathrm{a}}$ & $21^{\mathrm{a}}$ & $1 \mathrm{~b}$ & $3^{b}$ & $0^{b}$ & $4^{b}$ \\
\hline Nov/99 & $32^{\mathrm{a}}$ & $66^{\mathrm{a}}$ & $0^{b}$ & $0^{b}$ & $0^{b}$ & $0^{b}$ \\
\hline Feb/00 & $5^{b}$ & $2^{b}$ & $11^{\mathrm{a}}$ & $8^{a}$ & $2^{b}$ & $1^{b}$ \\
\hline Apr/00 & $2^{\mathrm{a}}$ & $0^{b}$ & $4^{\mathrm{a}}$ & $0^{b}$ & $5^{a}$ & $9^{\mathrm{a}}$ \\
\hline Total & 85 & 141 & 54 & 68 & 20 & 39 \\
\hline
\end{tabular}

$\overline{\text { Different letters }=\text { significant difference intra-sex in qui-square }}$ test $(\mathrm{p}<0.05)$.

edge and $15.7 \%$ were from the peridomicile habitat (Table II). There was no evidence that $L$. neivai movement was influenced by the wind, because in all the experiments large numbers of recaptured sand flies were in Shannon traps situated in different sites that were independent of the predominant wind direction.
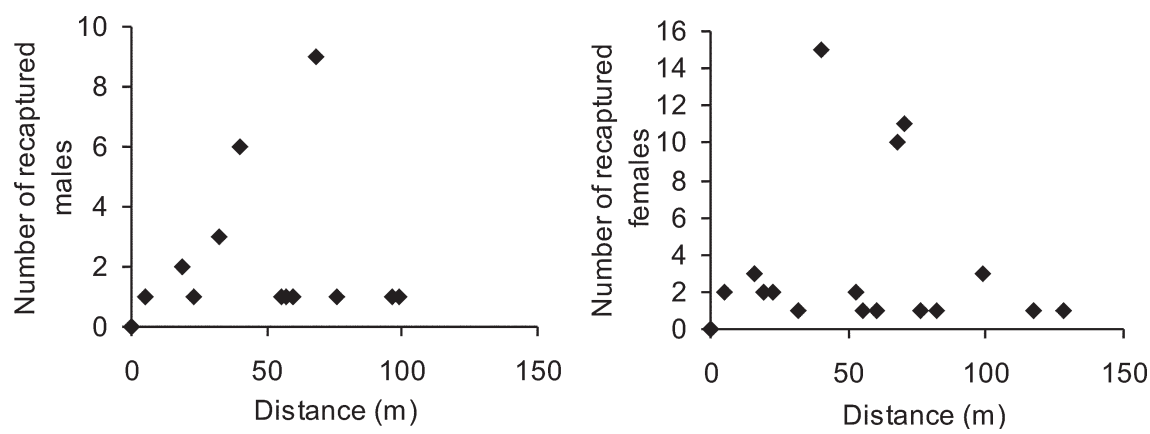

Fig. 4: relation between the total number of males and females Lutzomyia neivai recaptured in CDC traps set at different distances from the release points in rural area of Conchal municipality, state of São Paulo, during August 1999 to April 2000.

Males

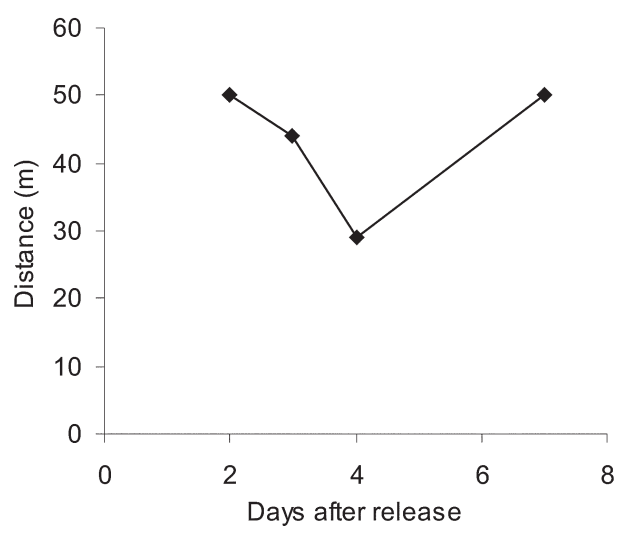

Females

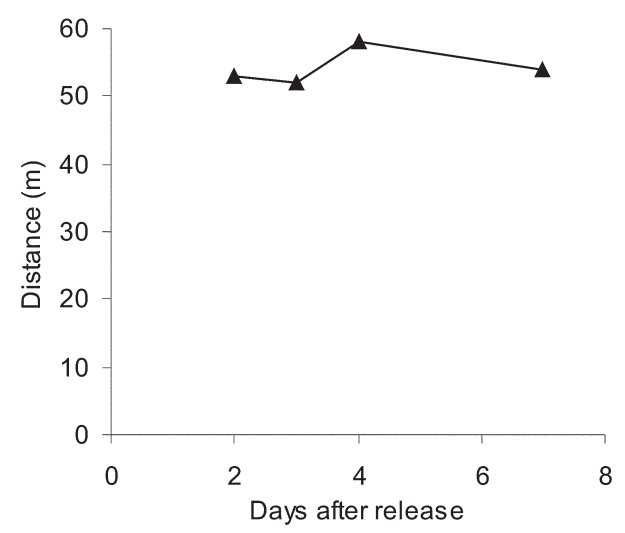

Fig. 5: mean distance dispersed per day by males and females Lutzomyia neivai recaptured in CDC traps in rural area of Conchal municipality, state of São Paulo, during November 1999. 


\section{DISCUSSION}

The comparable mortalities among marked and control groups of L. neivai in the laboratory experiments, coupled with the field recapture results, show that the marking device described in the present study can be safely used in other sand flies dispersal studies. Furthermore, this technique complies with one of the five basic assumptions of a mark-release-recapture method used to estimate the absolute size of population in nature (Southwood 1978) which is that the marked animal must not be affected by marking.

The overall recapture rate of L. neivai $(7.5 \%)$ was comparable with those reported by previous studies for other cutaneous leishmaniasis potential vectors in Neotropical region (Chaniotis et al. 1974, Alexander 1987, Alexander \& Young 1992).

The results of the arithmetic mean of dispersal distances (53 $\mathrm{m}$ for males and $55 \mathrm{~m}$ for females), the mean distance dispersed per day (bellow $60 \mathrm{~m}$ for males and females) and the maximum dispersal range ( $99 \mathrm{~m}$ for males and $128 \mathrm{~m}$ for females) indicates that the movements of $L$. neivai are spatially focal in our study area. These results agree with other sand flies dispersal studies in similar habitats of the Neotropical region. It is most probable, that the availability of diurnal resting sites, food sources, and breeding sites are in or near to the forest environment so that dispersion is not important (Chaniotis et al. 1974, Alexander \& Young 1992). Although the marked individuals were not released for a second time during the field experiments, the recapture of two females and two males up to 11 and 14 days after release, respectively, represent the higher survival for Neotropical sand flies in nature. Estimates of daily survival during the gonotrophic cycle and the absolute abundance are fundamental in evaluating the vectorial capacity of $L$. neivai and will be addressed in a future article.

The higher recapture of L. neivai females in Shannon traps situated in forest and forest edge $(84.3 \%)$ environments demonstrate the tendency of this species to remain on the forest border or to disperse to forest environment. On the other hand, the fact that approximately $16 \%$ of recaptured females occurred in Shannon traps situated in the peridomestic habitat support the hypothesis that domiciliary transmission results from females infected in an enzootic cycles that is probably situated in the nearby forest (Gomes et al. 1989, Gomes 1994, Lainson 1994).

Since the vector's dispersion is one of the major factors that determines the potential rate of pathogen dissemination, the focal dispersion of $L$. neivai suggests a low rate of L. (V.) braziliensis dissemination. Coupled to the dispersion to peridomicile habitat, the present data helps our understanding of the focal distribution of human cases and domiciliary transmission. This is the present epidemiological pattern of ACL in Southeastern region of Brazil in areas where L. neivai is the predominant species (Gomes 1992, 1994, Tolezano 1994). Besides this studies on the genetic structure of $L$. (V.) braziliensis populations have also indicated that they are focal (Ishikawa et al. 2002, Cupolillo et al. 2003) and that the reservoirs of this parasite also have focal habits (Brandão et al. 2003). The importance of the forest habitat and the dispersal potential of the vector provide important information that can be used to determine the feasibility of using "buffer zones" and their width, or the creation of vegetation-free belt between dwellings and the forest suggested by Alexander and Young (1992) as a potential alternative to chemical control used against the vectors. The recapture of one L. neivai female in a peridomicile at approximately $130 \mathrm{~m}$ from the release point situated in forest edge should be taken into consideration in the control activities against this suspected cutaneous leishmaniasis vector.

\section{ACKNOWLEDGMENTS}

To Dr Flávio AM dos Santos, Universidade Estadual de Campinas, for the statistical analysis. To Dr Jeffrey J Shaw for suggestions on the manuscript.

\section{REFERENCES}

Alexander B 2000. Sampling methods for phlebotomine sand flies. Med Vet Entomol 14: 109-122.

Alexander JB 1987. Dispersal of phlebotomine sand flies (Diptera: Psychodidae) in a Colombia coffee plantation. $J$ Med Entomol 24: 552-558.

Alexander JB, Young DG 1992. Dispersal of phlebotomine sand flies (Diptera: Psychodidae) in a Colombian focus of Leishmania (Viannia) braziliensis. Mem Inst Oswaldo Cruz 87: 397-403.

Andrade Filho JD, Galati EAB, Falcão AL 2003. Redescription of Nyssomyia intermedia (Lutz \& Neiva, 1912) and Nyssomyia neivai (Pinto, 1926) (Diptera: Psychodidae). Mem Inst Oswaldo Cruz, 98: 1059-1065.

Brandão-Filho SP, Brito ME, Carvalho FG, Ishikawa EA, Cupolillo E, Floeter-Winter L, Shaw JJ 2003. Wild and synanthropic hosts of Leishmania (Viannia) braziliensis in the endemic cutaneous leishmaniasis locality of Amaraji, Pernambuco State, Brazil. Trans R Soc Trop Med Hyg 97: 291-296.

Brenner JR, Wargo MJ, Stains GS, Mulla MS 1984. The dispersal of Culicoides mohave (Diptera: Ceratopogonidae) in the desert of southern California. Mosquito News 44: 343350.

Casanova C 2000. A soil emergence trap for collections of phlebotomine sand flies. Mem Inst Oswaldo Cruz 96: 273275.

Casanova C, Mayo RC, Rangel O, Mascarini LM, Pignatti MG, Galati EAB, Gomes AC 1995. Natural Lutzomyia intermedia (Lutz \& Neiva) infection in the Valley of Mogi-Guaçu River, State of São Paulo, Brazil. Bol Dir Malariol y San Amb 35 (Supl. 1): 77- 84.

Chaniotis BN, Correa MA, Tesh RD, Johnson KM 1974. Horizontal and vertical movements of phlebotomine sand flies in a Panamanian rain forest. J Med Entomol 11: 363-375.

Cupolillo E, Brahim LR, Toaldo CB, de Oliveira-Neto MP, de Brito ME, Falqueto A, de Farias Naiff M, Grimaldi Jr G 2003. Genetic polymorphism and molecular epidemiology of Leishmania (Viannia) braziliensis from different hosts and geographic areas in Brazil. J Clin Microbiol 41: 31263132.

Doha S, Shehata MG, El Said S, El Sawaf B 1991. Dispersal of 
Phebotomus papatasi (Scopoli) and P. langeroni Nitzulescu in El Hammam, Matrouh Governorate, Egypt. Ann Parasitol Human Comp 66: 69-76.

Dye C, Davies CR, Lainson R 1991. Communication among phlebotomine sand flies: a field study of domesticated Lutzomyia longipalpis populations in Amazonian Brazil. Anim Behav 42: 183-192.

Forattini OP 1973. Entomologia Médica, $4^{\circ}$ vol., Psychodidae; Plebotominae; Leishmanioses; Bartoneloses, Edgard Blucher/EDUSP, São Paulo, 658 pp.

Gomes AC 1992. Perfil epidemiológico da leishmaniose tegumentar americana no Brasil. An Bras Dermatol 67: 5560 .

Gomes AC 1994. Sand fly vectorial ecology in the State of São Paulo. Mem Inst Oswaldo Cruz 89: 457-460.

Gomes AC, Barata JMS, Rocha e Silva EO, Galati EAB 1989. Aspectos ecológicos da leishmaniose tegumentar americana. 6 - Fauna flebotomínea antropófila de matas residuais situadas na região centro-nordeste do estado de São Paulo, Brasil. Rev Inst Med Trop 31: 32- 39.

Gontijo CMF, Silva ES, Fuccio MB, Sousa MCA, Pacheco RS, Dias ES, Andrade JDF, Brazil RP, Melo MN 2002. Epidemiological studies of an outbreak of leishmaniasis in the Rio Jequitinhonha Valley, Minas Gerais, Brazil. Acta Trop 81: 143-150.

Ishikawa EA, Silveira FT, Magalhães AL, Guerra Junior RB, Melo MN, Gomes R, Silveira TG, Shaw JJ 2002. Genetic variation in populations of Leishmania species in Brazil. Trans R Soc Trop Med Hyg 96 (Suppl. 1): S111-121.

Kelly DW, Dye C 1997. Pheromones, kairomones and the aggregation dynamics of the sand fly Lutzomia longipalpis. Anim Behav 53: 721-731.

Killick-Kendrick R, Rioux JA, Bailly M, Guy MW, Wilkes TJ, Guy FM, Davidson I, Knechtli R, Ward RD, Guilvard E, Perieres J, Dubois H 1984. Ecology of leishmaniasis in the South of France. 20 - Dispersal of Phlebotomus ariasi Tonnoir, 1921 as a factor in the spread of the visceral leishmaniasis in the Cévennes. Ann Parasitol Hum Comp 59: 555-572.

Lainson R 1989. Demographic changes and their influence on the epidemiology of the American leishmaniasis. In MW Service ed. Demography and Vector-Borne Diseases, CRC Press, Boca Raton, FL, p. 85-106.

Lainson R, Shaw JJ, Silveira FT, Souza AAA, Braga R, Ishikawa EAY 1994. The dermal leishmaniasis of Brazil, with special reference to the eco-epidemiology of the disease in Amazonia. Mem Inst Oswaldo Cruz 89: 435-443.

Marcondes CB 1996. A redescription of Lutzomyia (Nyssomyia) intermedia (Lutz \& Neiva, 1912), and resurrection of $L$. neivai (Pinto, 1929) (Diptera, Psychodidae, Phlebotominae). Mem Inst Oswaldo Cruz 91: 457-462.

Marcondes CB, Lozovei AL, Vilela JH 1998. Distribuição geográfica de flebotomíneos do complexo Lutzomyia intermedia (Lutz \& Neiva, 1912). Rev Soc Bras Med Trop 31: 51-58.

Morrison AC, Ferro C, Morales A, Tesh RB, Wilson ML 1993. Dispersal of the sand fly Lutzomyia longipalpis (Diptera: Psychodidae) at an endemic focus of visceral leishmaniasis in Colombia. J Med Entomol 30: 427-35.

Pardo RH, Torres M, Morrison AC, Ferro C 1996. Effect of fluorescent powder on Lutzomyia longipalpis (Diptera: Psychodidae) and a simple device for marking sand flies. J Am Mosq Control Assoc 12: 235-242.

Rangel EF, Azevedo ACR, Andrade CA, Souza NA, Wermelinger ED 1990. Studies on sand fly fauna (Diptera: Psychodidae) in a focus of cutaneous leishmaniasis in Mesquita, Rio de Janeiro state, Brazil. Mem Inst Oswaldo Cruz 85: 39-45.

Salomón OD, Rossi GC, Cousiño B, Spinelli GR, Arias AR, Puerto DGL, Ortiz AJ 2003. Phlebotominae sand flies in Paraguay. Abundance distribution in the Southeastern region. Mem Inst Oswaldo Cruz 98: 185-190.

Salomón OD, Wilson ML, Munstermann LE, Travi BL 2004. Spatial and temporal patterns of phlebotomine sand flies (Diptera: Psychodidae) in a cutaneous leishmaniasis focus in northern Argentina. J Med Entomol 41: 33-39.

Southwood TRE 1978. Ecological Methods with Particular Reference to the Study of Insect Populations, 2nd ed., Chapman \& Hall, London, 524 pp.

Sokal RR, Rohlf FJ 1995. Biometry: the Principles and Practice of Statistics in Biologial Research, WH Freeman \& Co., New York, 887 pp.

Teodoro U, Silveira TGV, Santos DR, Santos ES, Santos AR, Oliveira O, Kühl JB 2001. Frequëncia da fauna de flebotomíneos no domicílio e em abrigos de animais domésticos no peridomicílio, nos municípios de Cianorte e Doutor Camargo - Estado do Paraná - Brasil. Rev Pat Tropical 30: 209-223.

Tolezano JE 1994. Ecoepidemiological aspects of american cutaneous leishmaniasis in the state of São Paulo, Brazil. Mem Inst Oswaldo Cruz 89: 427-34.

Vexenat JA, Barreto AC, Cuba CC, Marsden PD 1986. Características epidemiológicas da leishmaniose tegumentar americana em uma região endêmica do Estado da Bahia. II Fauna flebotomínica. Mem Inst Oswaldo Cruz 81: 293-301.

Young DG, Duncan MA 1994. Guide to the identification and geographic distribution of Lutzomyia sand flies in Mexico, the West Indies, Central and South America (Diptera: Psychodidae). Mem Amer Entomol Inst 54: 1-881. 